\title{
Gout impacts on function and health-related quality of life beyond associated risk factors and medical conditions: results from the KING observational study of the Italian Society for Rheumatology (SIR)
}

Carlo Alberto Scirè ${ }^{1,2^{*}}$, Maria Manara', Marco Amedeo Cimmino ${ }^{3}$, Marcello Govoni ${ }^{4}$, Fausto Salaffi ${ }^{5}$, Leonardo Punzi ${ }^{6}$, Maria Cristina Monti ${ }^{7}$, Greta Carrara ${ }^{1}$, Carlomaurizio Montecucco ${ }^{2}$, Marco Matucci-Cerinic ${ }^{8}$ and Giovanni Minisola9 ${ }^{9}$ for KING Study Collaborators

\begin{abstract}
Introduction: Gout is the most prevalent arthritis and significantly impacts on function and quality of life. Given that gout associates with disabling comorbid conditions, it is not clear whether such a complex of diseases accounts for the increased disability or if gout may play a role by itself. This study aims to evaluate the specific influence of gout and disease-related features on functional disability and health-related quality of life (HRQoL) in patients with gout followed in rheumatology clinics.
\end{abstract}

Methods: A random sample of patients was drawn from clinical registries of 30 rheumatology clinics across Italy. Sociodemographic, general health and gout-specific variables were collected. Functional disability and HRQoL were assessed by the health assessment questionnaire (HAQ) and the Physical and Mental Component Summary scores (PCS and MCS) of the Short Form-36 (SF-36). Crude and adjusted ordinal logistic and linear regression models were applied to investigate the specific contribution of different variables on HAQ and SF-36 scores. Results are presented as odds ratio (OR) or mean difference (MD) and 95\% confidence intervals.

Results: Out of 446 patients with gout, $90 \%$ were males with a mean age of 63.9 years and median disease duration of 3.8 years; the majority of patients were overweight or obese, and with several comorbidities; $21.1 \%$ showed at least moderate disability; the PCS score was significantly lower than expected age- and gender-matched samples in the general population, while MCS score was not. After adjusting for potential sociodemographic and general-health confounders, gout-specific variables significantly impacted on HAQ, including polyarticular involvement OR $3.82(1.63,8.95)$, presence of tophi OR $1.92(1.07,3.43)$ and recent attacks OR $2.20(1.27,3.81)$. Consistent results were found for PCS. The impairment of PCS compared to the general population was limited to patients with features of chronic gout. MCS was only affected by recent attacks (MD -2.72 [-4.58, -0.86]) and corticosteroid treatment $(-3.39[-5.30,-1.48])$.

Conclusions: The data from the KING study confirm that gout impacts on disability and provide evidence for an independent association of gout and gout-related features with functional outcome and HRQoL. This result supports the need to improve specific treatment in gout.

\footnotetext{
* Correspondence: c.scire@reumatologia.it

'Epidemiology Unit, Italian Society for Rheumatology, Via Turati 40, 20121,

Milano, Italy

Full list of author information is available at the end of the article
} 


\section{Introduction}

Gout is the most common arthritis in adults with a worldwide prevalence of 1 to $2 \%$ [1]. In Italy the prevalence of gout is lower, ranging from 0.5 to $0.9 \%$, although it is rapidly increasing as in other western countries $[2,3]$. Population aging, increased drug utilisation and changes in lifestyles and dietary habits may account for this increase over time [4].

In patients with gout, functional disability [5], impairment of health-related quality of life (HRQoL) and increased mortality have been reported [6]. Gout therefore emerges as a major public health issue. However, it is well known that gout is associated with several cardiovascular risk factors including hypertension, dyslipidaemia, insulin resistance, obesity, as well as renal failure [7]. Whether the impact of gout is related to the disease itself or whether it primarily arises from associated risk factors and medical conditions is still unclear [8].

Today, effective treatments are available for gout but it has not yet been determined whether, in order to minimise long-term detrimental outcomes, its prevention and management should primarily target risk factors and comorbidities rather than disease mechanisms [9]. The relevance of assessing patient-oriented outcomes, such as functional ability and HRQoL, has been recently recognised by the Outcome Measures in Rheumatology Clinical Trial (OMERACT) $[8,10,11]$.

Previous case-control and cross-sectional population studies have shown that HRQoL and functional impairment were mainly due to confounders, including sociodemographic characteristics and comorbidities, rather than due to gout itself $[12,13]$. These studies did not explore clinical characteristics in depth and hence drew conclusions on the overall population of patients with gout without determining the influence of specific features of the disease. Gout has a wide clinical heterogeneity that may reflect the varying impact on physical ability and HRQoL. Prognostic studies on convenience samples of patients with gout investigated the association between disease characteristics and outcomes; such studies identified as predictors acute symptoms, presence of tophi, previous and current joint involvement, and, under specific conditions, urate-lowering treatment (ULT), but they often selected chronic and refractory gout without controlling for several confounders [9,12,14-19]. Whether gout and gout severity variables themselves are independently associated with poor functional ability and HRQoL remains to be confirmed [8].

In 2011 the Italian Society for Rheumatology (SIR) established the Kick-off of the Italian Network for Gout (KING), a national multicentre cohort study that recruited patients with gout selected by random sampling from rheumatology centres across Italy. Using cross-sectional data from this ongoing study, this analysis explored the influence of disease-related features, derived from a detailed clinical examination, on functional ability and HRQoL in patients with a clinical diagnosis of gout and who are followed in rheumatology clinics. Potential confounders including sociodemographic variables and general health variables, such as comorbidities and lifestyle, were taken into account. The results of these analyses allowed one to evaluate the specific impact of gout, across its spectrum of disease severity, on functional disability and HRQoL.

\section{Patients and methods}

\section{Study design and recruitment}

This is a cross-sectional analysis of an ongoing multicentre cohort study including patients with a clinical diagnosis of gout from 30 rheumatology centres in Italy (KING Study, promoted by SIR; NCT01549210) recruited between June 2011 and January 2012. All Italian rheumatology centres were asked to participate. The cohort is a nationwide representative sample of patients referred to rheumatology clinics.

To limit selection bias arising from nonprobability samples (for example, consecutive sampling) resulting from the limited time span of recruitment and infrequent follow-up appointments [20], participants were selected from clinical registries by random cluster sampling. Rheumatologists sent a list of all patients registered in the previous 2 years at their clinics with a diagnosis of gout. Patients were then randomly selected from these registries by an independent investigator (CAS) at a central facility who also checked for duplicates between centres by using probability record linkage based on gender, date and place of birth. The selection complied with the Italian data protection regulations.

Rheumatologists confirmed from their clinical records that the patients selected had a diagnosis of gout. Patients were recruited by telephone following a rigorous contact protocol to optimise recruitment of patients. Patients included in the study sample did not systematically differ from the source population in terms of age, gender and follow-up duration.

A total of 450 patients were recruited but four of them were excluded because at baseline assessment they did not meet the inclusion criterion of clinical diagnosis of gout. The study flowchart is reported in Additional file 1.

The study protocol was approved by the ethics committees of the following institutions: IRCCS Policlinico S. Matteo Foundation of Pavia, San Martino Hospital of Genoa, University Hospital of Bologna, University Hospital of Ferrara, University Hospital of Firenze, University Hospital of Foggia, University Hospital of Messina, University Hospital of Padova, University Hospital of Palermo, University Hospital of Siena, University Hospital of Verona, University Hospital of San Camillo, Forlanini 
Hospital of Rome, Humanitas Institute of Milano, G. Pini institute of Milano, S. Giovanni Battista Hospital of Torino, Macchi Foundation of Varese, and the local health authorities of Barletta, Catania, Crotone, Cuneo, Marche, Milano, Roma, Pescara and Salerno. The study was conducted in accordance with the Declaration of Helsinki, and each patient provided written informed consent.

\section{Clinical assessment}

At baseline all patients underwent full clinical evaluation, which followed a structured case report form that included both general health and disease-specific variables.

General variables included sociodemographic data, lifestyle factors, the food-frequency questionnaire of the Italian National Institute for Statistics for national surveys, and comorbidities scored according to the SelfAdministered Comorbidity Questionnaire [21,22]. The Self-Administered Comorbidity Questionnaire score ranges from 0 to 36 since it includes 12 medical problems and allocates 1 point for the presence of each problem, another point if the patient receives treatment for it, and an additional point if the problem causes a limitation in function [21].

Gout-related variables included symptom duration, classification according to the 1977 preliminary American College of Rheumatology criteria [23], disease-related comorbidities (hypertension, dyslipidaemias, diabetes, cerebrovascular and cardiovascular disease and urinary stones), pattern of disease (such as number and site of involved joints, presence and site of tophi), previous and current treatment for gout, joint examination on $66 / 68$, measurement of tophi, a 0 to 10 numeric rating scale for pain, disease severity, general health and serum uric acid (sUA) concentration.

All patients completed the Italian versions of the Health Assessment Questionnaire Disability Index (HAQ-DI) and the Short-Form-36 (SF-36) [24,25].

To limit information bias and to improve overall reliability, all rheumatologists were instructed to collect the data and clinical measurements by following standard definitions and operating procedures. All data were also centrally checked for missing values and inconsistencies through a standardised procedure of data monitoring and cleaning.

\section{Variables: outcomes, predictors and confounders}

Functional disability assessed by the HAQ-DI was the primary outcome measure of this analysis. The HAQ-DI is a self-administered questionnaire validated for several forms of arthritis including gout and is recommended by OMERACT [10]. The HAQ-DI score (range 0 to 3 ) was categorised into three different classes of functional disability according to relevant cutoff values proposed by the developers and as applied in other arthritides: absent or mild ( 0 to 1 ), moderate ( $>1$ to 2 ) and severe ( $>2$ to 3 ) $[26,27]$.

HRQoL measured by the SF-36 questionnaire was the secondary outcome. The SF-36 is a widely used, selfadministered general health status instrument consisting of 36 items, which can be scored as two summary scores: Physical Component Summary (PCS) and Mental Component Summary (MCS) scores. The summary scores were normalised to the Italian population, where the mean score is 50 with a standard deviation of 10 $[25,28,29]$. A score below the mean score of 50 implies a lower health status as measured by the PCS and MCS. Clinically significant difference for the SF-36 summary scores was set at 2.5 as previously reported [30].

Disease-related variables were used as predictors and were coded as follows: symptom duration ( $>5$ years), cumulative joint involvement (1 joint, monoarticular; 2 to 4 joints, oligoarticular; $>4$ joints, polyarticular), number of attacks in the last year, attacks in the last month, presence of tophi, number of swollen joints, number of tender joints, sUA ( $<5 \mathrm{mg} / \mathrm{dl} ; \geq 5$ to $6 \mathrm{mg} / \mathrm{dl} ; \geq 6$ to $7 \mathrm{mg} / \mathrm{dl} ;>7$ $\mathrm{mg} / \mathrm{dl}$ ) [31], current ULT, current nonsteroidal antiinflammatory drugs or colchicine use, and systemic corticosteroid use at any time (previous or current).

The following general variables were classified as confounders: age, sex (male as reference), education (none or primary; secondary, upper secondary and tertiary education), employment (employed; unemployed; retired; unknown/other), smoking (current smoker; nonsmoker or exsmoker), body mass index category (underweight, $\leq 18.5$; normal weight, 18.5 to 24.9 ; overweight, 25 to 29.9; obesity, $\geq 30$ ), high alcohol consumption ( $>0.5$ litres of wine per day, beer more than occasionally or spirits more than occasionally).

Sample size was estimated based on the primary objective of the cohort study; that is, the evaluation of a prognostic model of progression of functional disability after 12 months of follow-up including a training set of 300 patients and a validation set of 150 patients.

\section{Statistical methods}

Descriptive measures of sociodemographic, general health and gout-related variables are presented as the absolute and relative frequency, mean and standard deviation or median and interquartile range based on their type and distribution.

Age-stratified and gender-stratified Italian normative data for the SF-36 were used to calculate the expected HRQoL for a standard population of similar age and gender structure [28]. The relationship between predictors and the HAQ score was modelled using ordinal regression [32]. Proportionality of odds across the HAQ groups was checked for each regression. Results are presented as odds ratios and $95 \%$ confidence intervals. The relationship 
between predictors and secondary outcomes (PCS and MCS) were analysed using linear regression models and the results are presented as mean difference and 95\% confidence intervals.

To evaluate the specific effect of gout-related variables, three different set of models were used for each outcome: unadjusted; adjusted for age and gender; and adjusted for age, gender, education, employment, body mass index, smoking, alcohol consumption and comorbidities. To compare expected with observed PCS scores, mean (and 95\% confidence interval) PCS scores according to different disease characteristics (disease duration, joint involvement, presence of tophi and number of attacks) and presence of comorbidities were obtained fitting fully adjusted linear regression models.

The overall percentage of missing information was less than $1 \%$ for variables included in the analyses. Given the high number of variables $(n=21)$, complete case analysis would have included only $83 \%$ of patients. Missing data were imputed using chained equations [33] and the fully adjusted analyses were performed on 10 multiple imputed datasets.

Analyses were performed using STATA software package (2009, release 11; StataCorp, TX, USA).

\section{Results}

A total of 446 patients with a clinical diagnosis of gout were included in this analysis. The main sociodemographic, general health and disease-related variables are summarised in Table 1.

The study sample included a majority of male (90\%) patients, with an overall mean (standard deviation) age of 63.9 (11.6) years, and a high frequency of Caucasian subjects (99\%). Male patients were younger than female patients with a mean (standard deviation) age of 63.6 (11.6) and 66.9 (11.8) years, respectively. The education background of the patients was mainly secondary school or lower. The majority of patients were overweight or obese and showed a high prevalence of high alcohol intake. More than $90 \%$ of patients had at least one comorbid condition according to the Self-Administered Comorbidity Questionnaire, mostly of a metabolic or cardiovascular nature. Most subjects had more than one comorbid condition with a median number (interquartile range) of 3 (1 to 4). More than $92 \%$ of patients fulfilled the preliminary American College of Rheumatology criteria for disease classification (22\% only based on crystal identification), and showed a median of 3.8 years of disease duration and a high prevalence of oligoarticular or polyarticular disease. About $30 \%$ of patients experienced an attack of gout within 1 month prior to the clinical evaluation, and 214 out of 410 (52.2\%) had sUA levels above $6 \mathrm{mg} / \mathrm{dl}$, despite 361/446 (80.9\%) being on ULT.
Table 1 Patients' characteristics

\begin{tabular}{|c|c|}
\hline Characteristic & \\
\hline$\overline{\text { Sex (male) }}$ & $403 / 446(90.4)$ \\
\hline Age (years) & $63.9(11.6)$ \\
\hline \multicolumn{2}{|l|}{ Employment } \\
\hline Employed & $137(30.7)$ \\
\hline Unemployed & $28(6.3)$ \\
\hline Retired & $226(59.6)$ \\
\hline Unknown/not declared & $15(3.4)$ \\
\hline \multicolumn{2}{|l|}{ Education } \\
\hline No or primary & $158(35.9)$ \\
\hline Secondary & $121(27.5)$ \\
\hline Upper secondary & $123(27.9)$ \\
\hline Tertiary & $38(8.6)$ \\
\hline Current smokers & 72/444 (16.2) \\
\hline Body mass index & $28.0(4.1)$ \\
\hline High alcohol consumers & $160(36.4)$ \\
\hline Comorbidities & $3(1$ to 4$)$ \\
\hline Hypertension & $313(70.3)$ \\
\hline Renal failure & $73(16.4)$ \\
\hline Osteoarthritis & $249(55.9)$ \\
\hline Cardiovascular disorders & $119(26.8)$ \\
\hline Diabetes & $64(14.4)$ \\
\hline Liver disorders & $36(8.1)$ \\
\hline Neoplasms & $28(6.29)$ \\
\hline Sangha comorbidity index (0 to 36 ) & $4(2$ to 7$)$ \\
\hline Fulfils preliminary ACR criteria & $411 / 445(92.4)$ \\
\hline Disease duration (years) & $3.8(1.5$ to 10.1$)$ \\
\hline \multicolumn{2}{|l|}{ Joint involvement } \\
\hline Monoarticular (1 joint) & $95(21.5)$ \\
\hline Oligoarticular (2 to 4 joints) & $264(59.7)$ \\
\hline Polyarticular (>4 joints) & $83(18.8)$ \\
\hline Swollen joints (0 to 66) & $0(0$ to 1$)$ \\
\hline Tender joints (0 to 68 ) & $1(0$ to 3$)$ \\
\hline Presence of tophi ${ }^{\mathrm{a}}$ & $87(19.9)$ \\
\hline Number of flares (12 months) & 1 (0 to 3 ) \\
\hline Flare (previous month) & $132(29.9)$ \\
\hline Serum urate level $(\mathrm{mg} / \mathrm{dl})^{\mathrm{b}}$ & $6.3(1.7)$ \\
\hline Previous corticosteroids & $125(28.0)$ \\
\hline Current NSAIDs or colchicine & $189(42.4)$ \\
\hline Allopurinol & $303(67.9)$ \\
\hline Febuxostat & $60(13.4)$ \\
\hline
\end{tabular}

Data presented as $n(\%)$, mean (standard deviation) or median (interquartile range). ACR, American College of Rheumatology; NSAID, nonsteroidal antiinflammatory drug. Data available for ${ }^{\mathrm{a}} 437$ subjects and ${ }^{\mathrm{b}} 410$ subjects.

According to the HAQ-DI score, at least moderate functional disability was observed in 94 out of 444 (21.1\%) patients, of whom 72 (16.22\%) showed moderate disability and $22(4.95 \%)$ showed severe disability (Figure 1$)$. The median (interquartile range) HAQ score was 0.25 (0 to 0.875). Overall, the physical components summarised by the PCS score were reduced as compared with the 


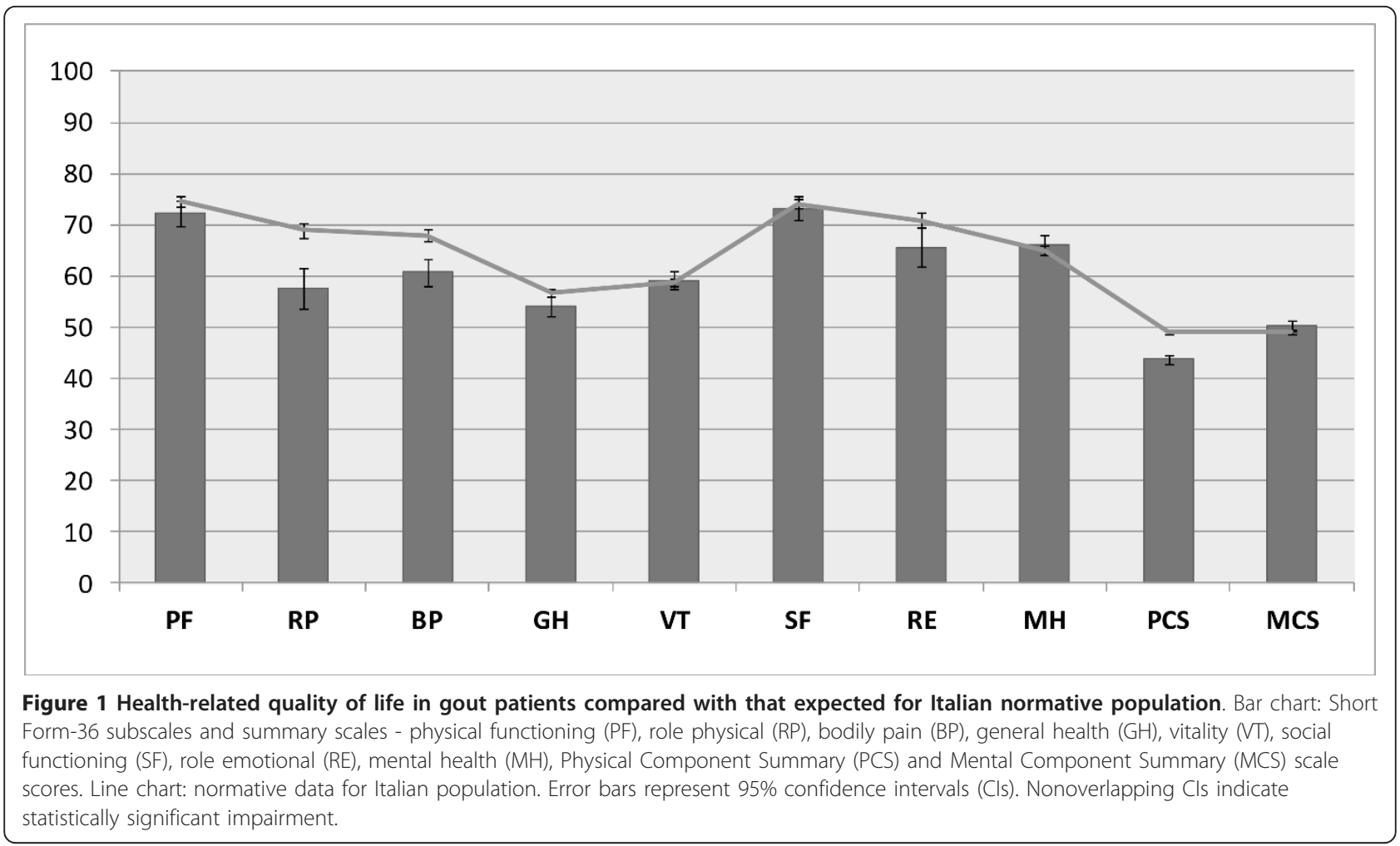

expected score for the age-matched and gender-matched general population (Figure 1). The MCS score did not differ from that for the general population.

Associations of sociodemographic, general health and disease-specific variables with functional disability and HRQoL were evaluated. The results of crude and adjusted analyses are presented in Tables 2 and 3.

Among sociodemographic data, older age, female gender and lower education significantly affected functional disability and the physical component of the SF-36 while only female gender influenced the mental component.

General health variables that significantly associated with higher HAQ-DI and lower PCS scores in ageadjusted and gender-adjusted models included comorbidities, overweight and obesity. Obesity was also associated with a statistically and clinically relevant lower MCS score.

Disease-related variables were strongly associated with functional disability and the physical component in the unadjusted analyses. After adjusting for age, gender and the other confounders, variables indicating chronic disease (disease duration, polyarticular joint involvement, presence of tophi) and uncontrolled joint inflammation (swollen and tender joints, attacks in the last months and current use of nonsteroidal anti-inflammatory drugs or colchicine) still showed statistically and clinically significant associations with the HAQ-DI and PCS scores. The MCS score was only influenced by acute symptomrelated variables.
Neither uncontrolled sUA nor ULT were associated with HAQ-DI or PCS outcomes in the fully adjusted analyses, even though subjects with high sUA levels $(>7 \mathrm{mg} / \mathrm{dl}$ ) showed statistically and clinically meaningful worse outcomes the analyses adjusted for age and gender.

Adjusted mean PCS scores, stratified by category of disease severity and presence of comorbidity, showed that subjects with monoarticular disease, absence of tophi and intercritical disease did not show significant impairment in the physical component of the PCS (Figure 2).

\section{Discussion}

Our results show that functional and HRQoL impairment observed in gout patients is not only due to general health variables, such as associated risk factors and comorbidities, but is also influenced by the activity and severity of several disease-related variables. Two studies previously attempted to answer the same question as the current study at a population level, suggesting that gout is not independently associated with HRQoL impairment. The first, a case-control study carried out in the United Kingdom using electronic records of general practitioners, reported an association between gout and impaired overall quality of life in a univariable analysis. Association was only evident in the physical domain of the World Health Organization Quality of Life - BREF instrument after adjusting for age, gender, body mass index, and medical/musculoskeletal comorbidities [12]. 
Table 2 Association between sociodemographic, general health and disease-specific variables to functional disability ${ }^{a}$

\begin{tabular}{|c|c|c|c|}
\hline \multirow[t]{2}{*}{ Variable } & \multicolumn{3}{|l|}{ HAQ-DI } \\
\hline & Crude OR (95\% Cl) & Adjusted OR $(95 \% \mathrm{Cl})^{\mathrm{b}}$ & Adjusted OR $(95 \% \mathrm{CI})$ \\
\hline \multicolumn{4}{|l|}{ Sociodemographic } \\
\hline Gender (female vs. male) & $6.27(3.37,11.64)$ & & \\
\hline Age (5 years) & $1.28(1.15,1.44)$ & & \\
\hline \multicolumn{4}{|l|}{ Education } \\
\hline No or primary & Reference & & \\
\hline Secondary & $0.48(0.27,0.84)$ & $0.66(0.36,1.20)$ & \\
\hline Upper secondary & $0.21(0.10,0.42)$ & $0.27(0.13,0.56)$ & \\
\hline Tertiary & $0.17(0.05,0.57)$ & $0.19(0.05,0.73)$ & \\
\hline \multicolumn{4}{|l|}{ Employment } \\
\hline Employed & Reference & & \\
\hline Unemployed & $5.85(2.21,15.48)$ & $2.49(0.85,7.31)$ & \\
\hline Retired & $3.57(1.81,7.03)$ & $2.21(0.92,5.28)$ & \\
\hline Unknown & - & - & \\
\hline \multicolumn{4}{|l|}{ General health variables } \\
\hline Comorbidity index & $1.22(1.15,1.29)$ & $1.16(1.09,1.24)$ & \\
\hline \multicolumn{4}{|l|}{ Body mass index } \\
\hline Normal & Reference & & \\
\hline Overweight & $1.82(0.90,3.68)$ & $2.44(1.14,5.22)$ & \\
\hline Obese & $2.71(1.28,5.73)$ & $4.02(1.78,9.07)$ & \\
\hline Current smokers & $0.99(0.53,1.85)$ & $1.37(0.71,2.64)$ & \\
\hline High alcohol consumers & $0.96(0.59,1.54)$ & $1.46(0.87,2.45)$ & \\
\hline \multicolumn{4}{|l|}{ Gout-related variables } \\
\hline Disease duration ( $>5$ years) & $1.98(1.24,3.14)$ & $2.12(1.30,3.46)$ & $2.03(1.22,3.40)$ \\
\hline \multicolumn{4}{|l|}{ Joint involvement } \\
\hline Monoarticular & Reference & & \\
\hline Oligoarticular (2 to 4 joints) & $1.75(0.89,3.45)$ & $1.99(0.96,4.09)$ & $1.49(0.70,3.16)$ \\
\hline Polyarticular (>4 joints) & $3.67(1.72,7.82)$ & $4.88(2.17,10.97)$ & $3.82(1.63,8.95)$ \\
\hline Number of attacks last year & $1.10(1.05,1.17)$ & $1.13(1.06,1.20)$ & $1.11(1.04,1.18)$ \\
\hline Attacks last month & $1.89(1.17,3.04)$ & $2.33(1.40,3.89)$ & $2.20(1.27,3.81)$ \\
\hline Presence of tophi & $2.14(1.28,3.59)$ & $2.06(1.19,3.56)$ & $1.92(1.07,3.43)$ \\
\hline Number of swollen joints & $1.25(1.16,1.35)$ & $1.25(1.15,1.35)$ & $1.23(1.13,1.33)$ \\
\hline Number of tender joints & $1.14(1.10,1.19)$ & $1.13(1.08,1.18)$ & $1.10(1.06,1.15)$ \\
\hline \multicolumn{4}{|l|}{ Serum uric acid } \\
\hline$<5 \mathrm{mg} / \mathrm{dl}$ & Reference & & \\
\hline 5 to $6 \mathrm{mg} / \mathrm{dl}$ & $1.18(0.57,2.42)$ & $1.25(0.58,2.69)$ & $1.24(0.56,2.74)$ \\
\hline 6 to $7 \mathrm{mg} / \mathrm{dl}$ & $0.94(0.42,2.10)$ & $1.20(0.51,2.79)$ & $0.83(0.34,2.06)$ \\
\hline$>7 \mathrm{mg} / \mathrm{dl}$ & $1.72(0.89,3.32)$ & $2.49(1.22,5.06)$ & $1.81(0.87,3.74)$ \\
\hline Urate-lowering treatment & $1.02(0.57,1.81)$ & $1.11(0.59,2.09)$ & $1.06(0.55,2.03)$ \\
\hline Current NSAIDs or colchicine & $3.17(1.89,5.33)$ & $3.24(1.87,5.61)$ & $2.57(1.40,4.72)$ \\
\hline Previous corticosteroids & $1.87(1.15,3.05)$ & $1.76(1.04,2.97)$ & $1.64(0.93,2.89)$ \\
\hline
\end{tabular}

NSAID, nonsteroidal anti-inflammatory drug. ${ }^{a}$ Assessed by the Health Assessment Questionnaire Disability Index (HAQ-DI). ${ }^{b}$ Adjusted for age and gender. 'Adjusted for age, gender, comorbidities, body mass index, smoking, high alcohol consumption, education and employment (on 10 imputed datasets).

This association was only slightly statistically significant and of unclear clinical relevance. A second populationbased survey, carried out from the US veterans database, found poorer HRQoL and higher functional limitation in patients with gout in unadjusted analyses that disappeared after controlling sociodemographic and comorbidity data [13]. These population studies, even limited by low response rates and incomplete clinical assessment, certainly captured the real distribution of gout severity, including a higher prevalence of cases with mild disease.

In our study we included a probability sample of patients with a clinical diagnosis of gout confirmed by a rheumatologist and we assessed functional disability and HRQoL using the tools recommended by OMERACT [10]. 
Table 3 Association between sociodemographic, general health and disease-specific variables to health-related quality of life ${ }^{a}$

\begin{tabular}{|c|c|c|c|c|c|c|}
\hline & \multicolumn{3}{|l|}{ SF-36 PCS } & \multicolumn{3}{|l|}{ SF-36 MCS } \\
\hline & $\begin{array}{l}\text { Crude MD } \\
(95 \% \mathrm{Cl})\end{array}$ & $\begin{array}{l}\text { Adjusted MD } \\
(95 \% \mathrm{Cl})^{\mathrm{b}}\end{array}$ & $\begin{array}{l}\text { Adjusted MD } \\
(95 \% \mathrm{CI})^{\mathrm{c}}\end{array}$ & $\begin{array}{l}\text { Crude MD } \\
(95 \% \mathrm{Cl})\end{array}$ & $\begin{array}{l}\text { Adjusted MD } \\
(95 \% \mathrm{Cl})^{\mathrm{b}}\end{array}$ & $\begin{array}{l}\text { Adjusted MD } \\
(95 \% \mathrm{Cl})^{\mathrm{c}}\end{array}$ \\
\hline \multicolumn{7}{|l|}{$\begin{array}{l}\text { Sociodemographic } \\
\text { variables }\end{array}$} \\
\hline Gender (female vs. male) & $\begin{array}{l}-7.37(-10.67 \\
-4.08)\end{array}$ & & & $-3.45(-6.44,-0.45)$ & & \\
\hline Age (5 years) & $-1.04(-1.45,-0.64)$ & & & $-0.15(-0.52,0.23)$ & & \\
\hline \multicolumn{7}{|l|}{ Education } \\
\hline No or primary & Reference & & & Reference & & \\
\hline Secondary & $1.44(-0.96,3.84)$ & $-0.26(-2.69,2.18)$ & & $0.52(-1.68,2.73)$ & $0.42(-1.90,2.73)$ & \\
\hline Upper secondary & $5.71(3.32,8.10)$ & $3.95(1.48,6.41)$ & & $2.15(-0.06,4.35)$ & $2.11(-0.24,4.45)$ & \\
\hline Tertiary & $5.40(1.84,8.97)$ & $3.84(0.26,7.41)$ & & $2.30(-0.98,5.58)$ & $2.46(-0.94,5.86)$ & \\
\hline \multicolumn{7}{|l|}{ Employment } \\
\hline Employed & Reference & & & Reference & & \\
\hline Unemployed & $\begin{array}{l}-6.05(-10.16 \\
-1.94)\end{array}$ & $-3.10(-7.31,-1.11)$ & & $-2.74(-6.50,1.03)$ & $-1.83(-5.77,2.12)$ & \\
\hline Retired & $-4.59(-6.69,-2.49)$ & $-1.99(-4.85,0.88)$ & & $-0.21(-2.13,1.71)$ & $0.34(-2.34,3.01)$ & \\
\hline Unknown & - & - & & - & - & \\
\hline \multicolumn{7}{|l|}{$\begin{array}{l}\text { General health } \\
\text { variables }\end{array}$} \\
\hline Comorbidity index & $-1.12(-1.34,-0.90)$ & $-0.98(-1.22,-0.74)$ & & $-0.58(-0.80,-0.37)$ & $-0.62(-0.85,-0.39)$ & \\
\hline \multicolumn{7}{|l|}{ Body mass index } \\
\hline Normal & Reference & & & Reference & & \\
\hline Overweight & $-2.47(-4.97,0.04)$ & $-2.98(-5.38,-0.58)$ & & $-1.06(-3.32,1.20)$ & $-1.45(-3.71,0.81)$ & \\
\hline Obese & $-4.87(-7.73,-2.01)$ & $-5.79(-8.51,-3.06)$ & & $-2.35(-4.92,0.22)$ & $-2.72(-5.29,-0.16)$ & \\
\hline Current smokers & $0.04(-2.60,2.67)$ & $-0.90(-3.45,1.64)$ & & $0.47(-1.9,2.84)$ & $0.3(-2.08,2.68)$ & \\
\hline High alcohol consumers & $0.57(-1.47,2.60)$ & $-0.58(-2.56,1.39)$ & & $-0.94(-2.77,0.88)$ & $-1.33(-3.17,0.52)$ & \\
\hline \multicolumn{7}{|l|}{$\begin{array}{l}\text { Gout-related } \\
\text { variables }\end{array}$} \\
\hline Disease duration ( $>5$ years) & $-2.54(-4.49,-0.58)$ & $-2.37(-4.25,-0.49)$ & $-1.70(-3.45,0.05)$ & $-2.54(-4.29,-0.79)$ & $-2.61(-4.35,-0.86)$ & $-2.08(-3.79,-0.37)$ \\
\hline \multicolumn{7}{|l|}{ Joint involvement } \\
\hline Monoarticular & Reference & & & Reference & & \\
\hline Oligoarticular (2 to 4 joints) & $-3.13(-5.53,-0.73)$ & $-3.35(-5.64,-1.06)$ & $-2.22(-4.38,-0.07)$ & $0.40(-1.78,2.57)$ & $0.27(-1.90,2.44)$ & $0.96(-1.18,3.10)$ \\
\hline Polyarticular (>4 joints) & $-5.66(-8.69,-2.62)$ & $-5.92(-8.82,-3.01)$ & $-3.79(-6.55,-1.04)$ & $-1.05(-3.80,1.70)$ & $-1.25(-4.00,1.50)$ & $0.42(-2.30,3.16)$ \\
\hline Number of attacks last year & $-0.70(-0.94,-0.47)$ & $-0.71(-0.93,-0.49)$ & $-0.56(-0.77,-0.36)$ & $-0.45(-0.66,-0.24)$ & $-0.44(-0.65,-0.23)$ & $-0.34(-0.55,-0.13)$ \\
\hline Attacks last month & $\begin{array}{l}-8.18(-10.15 \\
-6.20)\end{array}$ & $-8.62(-10.49,-6.76)$ & $-8.13(-9.88,-6.38)$ & $-3.22(-5.09,-1.35)$ & $-3.33(-5.20,-1.47)$ & $-2.72(-4.58,-0.86)$ \\
\hline Presence of tophi & $-4.72(-7.15,-2.30)$ & $-4.16(-6.50,-1.83)$ & $-3.20(-5.41,-0.99)$ & $0.56(-1.62,2.75)$ & $0.71(-1.47,2.89)$ & $1.26(-0.88,3.40)$ \\
\hline Number of swollen joints & $-0.91(-1.17,-0.65)$ & $-0.78(-1.04,-0.53)$ & $-0.54(-0.79,-0.29)$ & $-0.40(-0.64,-0.16)$ & $-0.37(-0.62,-0.13)$ & $-0.20(-0.45,0.04)$ \\
\hline Number of tender joints & $-0.64(-0.79,-0.49)$ & $-0.58(-0.73,-0.42)$ & $-0.39(-0.55,-0.24)$ & $-0.38(-0.52,-0.24)$ & $-0.36(-0.51,-0.21)$ & $-0.24(-0.39,-0.09)$ \\
\hline \multicolumn{7}{|l|}{ Serum uric acid } \\
\hline$<5 \mathrm{mg} / \mathrm{dl}$ & Reference & & & Reference & & \\
\hline 5 to $6 \mathrm{mg} / \mathrm{dl}$ & $-0.09(-3.14,2.96)$ & $-0.15(-3.06,2.76)$ & $-0.60(-3.24,2.02)$ & $-0.2(-2.97,2.57)$ & $-0.23(-2.99,2.52)$ & $-0.66(3.19,1.86)$ \\
\hline 6 to $7 \mathrm{mg} / \mathrm{dl}$ & $-0.12(-3.09,2.86)$ & $-0.60(-3.46,2.26)$ & $0.48(-2.32,3.29)$ & $-1.68(-4.38,1.03)$ & $-1.71(-4.42,0.99)$ & $-0.75(-3.55,2.04)$ \\
\hline$>7 \mathrm{mg} / \mathrm{dl}$ & $-1.78(-4.56,0.99)$ & $-2.95(-5.63,-0.28)$ & $-2.06(-4.51,0.38)$ & $-1.45(-3.98,1.07)$ & $-1.78(-4.31,0.76)$ & $-1.00(-3.39,1.38)$ \\
\hline Urate-lowering treatment & $0.41(-2.05,2.87)$ & $0.37(-2.01,2.75)$ & $0.49(-1.71,2.69)$ & $0.27(-1.94,2.47)$ & $0.06(-2.16,2.27)$ & $0.03(-2.12,2.19)$ \\
\hline Current NSAIDs or colchicine & $-7.03(-8.95,-5.11)$ & $-6.67(-8.52,-4.82)$ & $-5.47(-7.38,-3.56)$ & $-2.79(-4.57,-1.00)$ & $-2.53(-4.32,-0.75)$ & $-2.13(-4.04,-0.23)$ \\
\hline Previous corticosteroids & $-5.10(-7.26,-2.95)$ & $-4-67(-6.75,-2.59)$ & $-3.51(-5.46,-1.26$ & $-4.15(-6.06,-2.23)$ & $-3.90(-5.83,-1.98)$ & $-3.39(-5.30,-1.48)$ \\
\hline
\end{tabular}

${ }^{a}$ Assessed by the Short Form-36 (SF-36) questionnaire, physical and mental summary score. Cl, confidence interval; MCS, Mental Component Summary; MD, mean difference; PCS, Physical Component Summary. ${ }^{a}$ Adjusted for age and gender. ${ }^{\text {b} A d j u s t e d ~ f o r ~ a g e, ~ g e n d e r, ~ c o m o r b i d i t i e s, ~ b o d y ~ m a s s ~ i n d e x, ~ s m o k i n g, ~ h i g h ~ a l c o h o l ~}$ consumption, education and employment (on 10 imputed datasets). 


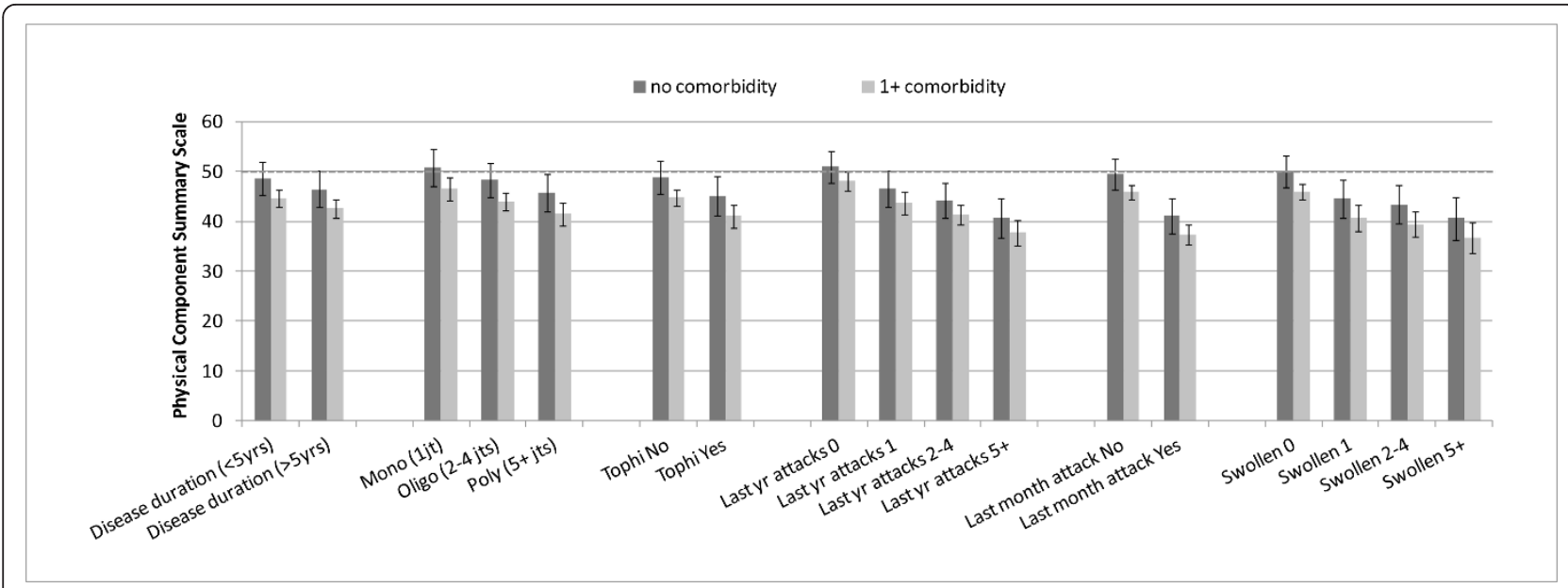

Figure 2 Mean Physical Component Summary scores according to different disease characteristics and presence of comorbidities. Error bars represent $95 \%$ confidence intervals (Cls). Cls not crossing the expected value of 50 (dashed line) indicate statistically significant impairment..

All patients were also directly assessed for sociodemographic, lifestyle and clinical variables in order to control a number of potential confounders. The results of the fullyadjusted models indicated that the association between disease-specific variables and functional disability, as assessed by HAQ-DI and PCS, are both statistically and clinically meaningful. To estimate the specific influence of disease-related variables on the PCS compared with the expected from the general population, the multivariable models were applied to obtain the adjusted mean PCS score for different levels of disease severity variables. The subgroup of patients with monoarticular disease, a low number of attacks and an absence of tophi did not show any significant impairment of the physical component of the SF-36 when compared with that of the general population. This result may partially explain the weakness of independent association between gout and disability or poor HRQoL in the general population given that population-based studies are likely to have a considerable number of subjects with a single attack or intercritical gout $[12,13]$. Disease-associated impairment of HRQoL thus seems to be related to a subgroup of patients with chronic gout while the physical impairment of subjects with mild disease is mainly due to general risk factors and concurrent medical conditions.

In our study, another significant finding is the identification of a number of disease-related factors associated with a worse outcome. The number of joints cumulatively involved was one of the major factors independently associated with increased presence of functional disability and worsening of the SF-36 physical component. This has been previously demonstrated for the number of involved joints against the PCS and MCS and for the disease-specific HRQoL instrument Gout Impact Scale $[8,17]$. Other findings are also highly consistent with the existing literature: the presence of tophi, as well as factors indicating active disease (such as number of swollen and tender joints, frequency of attacks) $[16,17,34]$, have been reported as major predictors of functional disability $[14,16]$ and poor HRQoL [16,34]. Our data confirm such associations and provide fully adjusted estimates by analysing the impact of every single variable using clinically relevant cutoff values or meaningful differences from tools validated for gout.

Our study confirms the lack of association between cross-sectional sUA levels and HAQ-DI or SF-36 dimensions $[12,14,16]$, while other studies reported a significant association with longitudinal levels of sUA $[9,34]$. This result might be partially explained by the fact that patients with more severe disease might be treated more aggressively, and therefore they exhibit a relatively better level of sUA than patients with mild disease. Furthermore, despite the relevance of sUA as a biomarker in gout [11], the effect on the outcome of severe disease is likely to be reached by a persistent control of sUA over time [35].

The mental component of the SF-36 is not generally affected in patients with gout $[12,13,17,35]$. Main clinical characteristics influencing the MCS score are variables of acute disease such as gout attacks, tender joints and the daily use of nonsteroidal anti-inflammatory drugs $[12,16]$. Our results confirmed these previous findings and further showed that the use of systemic glucocorticoids may also impact on the mental component of the SF-36. This finding, already reported by Roddy and colleagues [12], should be interpreted in the context of more severe disease leading to the prescription of corticosteroids rather than as an effect on disease severity an issue that is still to be resolved.

This study has some limitations. Results may not be translated to the whole population of gout patients since 
participants were recruited from the registries of rheumatology clinics that usually follow up patients with chronic disease and atypical presentations. However, demographic and clinical characteristics are consistent with those reported in a recent descriptive study carried out in a nationwide representative primary care register in Italy [2]. Given that the majority of rheumatology clinics were hospital based, recruitment of patients can be further biased towards gout patients with more severe comorbidities. However, a detailed clinical evaluation in a rheumatological setting has included patients with accurate diagnosis of gout (92\% fulfilled the preliminary American College of Rheumatology criteria) and allowed analyses for different levels of disease severity. The cross-sectional design is essentially descriptive and exploratory since it does not allow for the ascertainment of temporal relationship between clinical characteristics, treatment or modification of risk factors on outcomes.

\section{Conclusions}

The KING study provides evidence for an independent association of gout and gout-related characteristics with functional outcome and HRQoL. In patients with chronic gout, the study also confirms the well-known influence of sociodemographic characteristics and comorbidities on the disease outcomes. These findings support the need for an integrated therapeutic approach, which combines specific disease control to limit progression of acute or intercritical to chronic gout and management of concomitant risk factors and medical conditions.

\section{Additional material}

\section{Additional file 1: is a flowchart of the KING study (cross-sectional)}

\footnotetext{
Abbreviations

HAQ-DI: Health Assessment Questionnaire Disability Index; HRQoL: healthrelated quality of life; KING: Kick-off of the Italian Network for Gout; MCS: Mental Component Summary; OMERACT: Outcome Measures in Rheumatology Clinical Trial; PCS: Physical Component Summary; SF-36: Short Form-36; SIR: Italian Society for Rheumatology; sUA: serum uric acid; ULT: urate-lowering treatment; VT: vitality.

\section{Competing interests}

The authors declare that they have no competing interests.

\section{Authors' contributions}

CAS, MAC, MM, CM, MG, GM, FS, LP and MM-C planned the study. All the authors collected data. CAS, MCM and GC analysed data. CAS supervised the project and wrote the first draft. All authors critically revised and approved the final manuscript.

\section{Acknowledgements}

The authors would like to acknowledge the contribution of the entire KING staff including other collaborators and research nurses. They are also grateful to the rheumatologists of the KING centres for their former data collection and for making available their registers of patients with gout. The KING
}

study is funded by SIR as part of the Epidemiology Unit development programme.

KING study group: Alessandra Galossi, UOC Medicina Interna ad indirizzo Epato-Gastroenterologico, AO S. Giuseppe, Marino (RM); Ciro Lauriti, Rheumatology Unit, Ospedale Civile Pescara, Pescara (PE); Elena Fracassi, Rheumatology Unit, Azienda Integrata Ospedale -Università di Verona, Verona (VR); Enrico Selvi, Rheumatology Unit, Policlinico 'Le Scotte', Siena (SI); Enrico Tirri, Dipartimento di Scienze Mediche - UOSD di Reumatologia, Ospedale San Giovanni Bosco, Napoli (NA); Federica Furini, Rheumatology Unit, Department of Medical Sciences, University of Ferrara, Azienda Ospedaliero - Universitaria S. Anna, Ferrara (FE); Flora Inverardi, Chair and Unit of Rheumatology, IRCCS Fondazione Policlinico San Matteo - Università di Pavia, Pavia (PV); Francesco Porta, Dipartimento di medicina clinica e sperimentale, SOD Reumatologia, AOUC, University of Firenze, Firenze (FI); Francesco Venturino, Rheumatology Unit, Casa di Cura Reumatologica Oliveti Cotronei (KR); Franco Capsoni, Unità Operativa Reumatologia Universitaria, Istituto Ortopedico Galeazzi - University of Milan, Milano (MI); Giandomenico Sebastiani, Rheumatology Unit, Azienda Ospedaliera San Camillo - Forlanini, Roma (RM); Gianluigi Fabbriciani, Division of Rheumatology and Clinical Immunology, Humanitas Clinical and Research Center, Rozzano (MI); Giovanni D'Avola, Rheumatology Unit, ASP3 Catania, Catania (CT); Giulia Botticella, Clinica Reumatologica Dipartimento di Medicina Interna e Specialità Mediche, University of Genova, Genova (GE); Giulia Seminara, Rheumatology Unit, ASO S Croce e Carle Cuneo (CN); Giuseppe D'Alessandro, SS di Malattie Apparato Osteoarticolare ed Immunoproliferative, Azienda Ospedaliero-Universitaria 'Ospedali Riuniti' di Foggia, Foggia (FG); Leonardo Santo, Rheumatology Unit, ASL BT - DSS 4 Barletta, Barletta (BT); Lorena Longato, Ambulatorio di Reumatologia, Poliambulatorio ASL, ASL Biella, Biella (BI); Luigi Sinigaglia, Struttura Complessa di Reumatologia DH, Istituto Ortopedico G. Pini, Milano (MI); Marco Atteritano, Unit of Rheumatology, Department of Clinical and Experimental Medicine University of Messina, Messina (ME); Marco Broggini, SSD di Reumatologia, A.O. Ospedale di Circolo e Fondazione Macchi, Varese (VA); Marta Caprioli, UO di Medicina Interna, Istituto Clinico Beato Matteo, Vigevano (PV); Marta Favero, Rheumatology Unit, Department of Medicine DIMED, University Hospital of Padova, Padova (PD); Salvatore Sallì,

Rheumatology Unit, Policlinico Universitario Paolo Giaccone, Palermo (PA); Simone Parisi, Rheumatology Unit A.O. Città della Salute e della Scienza di Torino, Torino (TO); Stefania Corvaglia, Rheumatology Unit, Azienda Ospedaliera Universitaria di Bologna - Policlinico S. Orsola Malpighi, Bologna (BO); Vittorio Veneto, Rheumatology Unit, Ospedale 'M. Scarlato' ASL Salerno, Scafati (SA).

\section{Authors' details}

'Epidemiology Unit, Italian Society for Rheumatology, Via Turati 40, 20121, Milano, Italy. ${ }^{2}$ Division of Rheumatology, IRCCS Policlinico San Matteo Foundation, University of Pavia, Viale Golgi 19, 27100, Pavia, Italy. ${ }^{3}$ Clinica Reumatologica, Dipartimento di Medicina Interna e Specialità Mediche, University of Genova, V.le Benedetto XV 6, 16132, Genova, Genova, Italy. ${ }^{4}$ Rheumatology Unit, Department of Medical Sciences, University of Ferrara Azienda Ospedaliero-Universitaria S. Anna, Via Aldo Moro 8, 44124, Cona, Ferrara, Italy. ${ }^{5}$ Department of Molecular and Clinical Sciences - DISCLIMO, Polytechnic University of Marche, Via Tronto 10/a, 60020, Torrette di Ancona, Ancona, Italy. ${ }^{6}$ Rheumatology Unit, Department of Medicine DIMED, University of Padova, Via Giustiniani 2, 35122, Padova, Italy. ${ }^{7}$ Department of Public Health, Experimental and Forensic medicine, University of Pavia, Via Forlanini 2, 27100, Pavia, Italy. ${ }^{8}$ Department of Rheumatology AVC, Department of Biomedicine \& Division of Rheumatology AOUC, Department of Medicine \& Denothe Centre, University Florence, Largo Brambilla 3, 50134, Firenze, Italy. ${ }^{9}$ Rheumatology Unit, Azienda Ospedaliera San Camillo, Circ. Gianicolense 87, 00152 Roma, Italy.

Received: 23 January 2013 Revised: 13 April 2013 Accepted: 3 September 2013 Published: 3 September 2013

\section{References}

1. Smith EU, az-Torne C, Perez-Ruiz F, March LM: Epidemiology of gout: an update. Best Pract Res Clin Rheumatol 2010, 24:811-827.

2. Trifirò G, Morabito P, Cavagna L, Ferrajolo C, Pecchioli S, Simonetti M, Bianchini E, Medea G, Cricelli C, Caputi AP, Mazzaglia G: Epidemiology of 
gout and hyperuricaemia in Italy during the years 2005-2009: a nationwide population-based study. Ann Rheum Dis 2013, 72:694-700.

3. Salaffi F, De AR, Grassi W: Prevalence of musculoskeletal conditions in an Italian population sample: results of a regional community-based study. I. The MAPPING study. Clin Exp Rheumatol 2005, 23:819-828.

4. Brook RA, Kleinman NL, Patel PA, Melkonian AK, Brizee TJ, Smeeding JE, Joseph-Ridge N: The economic burden of gout on an employed population. Curr Med Res Opin 2006, 22:1381-1389.

5. ten Klooster PM, Vonkeman HE, van de Laar MA: Disability due to gouty arthritis. Curr Opin Rheumatol 2012, 24:139-144.

6. Lottmann K, Chen X, Schadlich PK: Association between gout and all-cause as well as cardiovascular mortality: a systematic review. Curr Rheumatol Rep 2012, 14:195-203.

7. Zhu Y, Pandya BJ, Choi HK: Comorbidities of gout and hyperuricemia in the US general population: NHANES 2007-2008. Am J Med 2012, 125:679-687.

8. Kim SY, Choi HK: Gout and quality of life. J Rheumatol 2009, 36:865-868.

9. Doherty M, Jansen TL, Nuki G, Pascual E, Perez-Ruiz F, Punzi L, So AK, Bardin T: Gout: why is this curable disease so seldom cured? Ann Rheum Dis 2012, 71:1765-1770.

10. Singh JA, Taylor WJ, Simon LS, Khanna PP, Stamp LK, McQueen FM, Neogi T, Gaffo AL, Becker MA, MacDonald PA, Dabbous O, Strand V, Dalbeth ND, Aletaha D, Edwards NL, Schumacher HR Jr: Patient-reported outcomes in chronic gout: a report from OMERACT 10. J Rheumatol 2011, 38:1452-1457.

11. Stamp LK, Khanna PP, Dalbeth N, Boers M, Maksymowych WP, Schumacher HR, Becker MA, MacDonald PA, Edwards NL, Singh JA, Simon LS, McQueen FM, Neogi T, Gaffo AL, Strand V, Taylor WJ: Serum urate in chronic gout - will it be the first validated soluble biomarker in rheumatology? J Rheumatol 2011, 38:1462-1466.

12. Roddy $E$, Zhang W, Doherty M: Is gout associated with reduced quality of life? A case-control study. Rheumatology (Oxford) 2007, 46:1441-1444.

13. Singh JA, Strand V: Gout is associated with more comorbidities, poorer health-related quality of life and higher healthcare utilisation in US veterans. Ann Rheum Dis 2008, 67:1310-1316.

14. Alvarez-Nemegyei J, Cen-Piste JC, Medina-Escobedo M, Villanueva-Jorge S: Factors associated with musculoskeletal disability and chronic renal failure in clinically diagnosed primary gout. J Rheumatol 2005, 32:1923-1927

15. Dalbeth N, Collis J, Gregory K, Clark B, Robinson E, McQueen FM: Tophaceous joint disease strongly predicts hand function in patients with gout. Rheumatology (Oxford) 2007, 46:1804-1807.

16. Becker MA, Schumacher HR, Benjamin KL, Gorevic P, Greenwald M, Fessel J, Edwards L, Kawata AK, Frank L, Waltrip R, Maroli A, Huang B, Sundy JS: Quality of life and disability in patients with treatment-failure gout. J Rheumatol 2009, 36:1041-1048.

17. Lee SJ, Hirsch JD, Terkeltaub R, Khanna D, Singh JA, Sarkin A, Kavanaugh A: Perceptions of disease and health-related quality of life among patients with gout. Rheumatology (Oxford) 2009, 48:582-586.

18. Khanna PP, Perez-Ruiz F, Maranian P, Khanna D: Long-term therapy for chronic gout results in clinically important improvements in the healthrelated quality of life: short form-36 is responsive to change in chronic gout. Rheumatology (Oxford) 2011, 50:740-745.

19. Dalbeth N, Petrie KJ, House M, Chong J, Leung W, Chegudi R, Horne A, Gamble G, McQueen FM, Taylor WJ: Illness perceptions in patients with gout and the relationship with progression of musculoskeletal disability. Arthritis Care Res (Hoboken) 2011, 63:1605-1612.

20. Gonzalez-Alvaro I, Carmona L, Balsa A, Sanmarti R, Belmonte MA, Tena X: Patterns of disease modifying antirheumatic drug use in a Spanish cohort of patients with rheumatoid arthritis. J Rheumatol 2003, 30:697-704.

21. Sangha O, Stucki G, Liang MH, Fossel AH, Katz JN: The Self-Administered Comorbidity Questionnaire: a new method to assess comorbidity for clinical and health services research. Arthritis Rheum 2003, 49:156-163.

22. Salaffi F, Carotti M, Gasparini S, Intorcia M, Grassi W: The health-related quality of life in rheumatoid arthritis, ankylosing spondylitis, and psoriatic arthritis: a comparison with a selected sample of healthy people. Health Qual Life Outcomes 2009, 7:25.

23. Wallace SL, Robinson H, Masi AT, Decker JL, McCarty DJ, Yu TF: Preliminary criteria for the classification of the acute arthritis of primary gout. Arthritis Rheum 1977, 20:895-900.
24. Ranza R, Marchesoni A, Calori G, Bianchi G, Braga M, Canazza S, Canesi B, Fumagalli M, Mastaglio C, Mathieu A, et al: The Italian version of the Functional Disability Index of the Health Assessment Questionnaire. A reliable instrument for multicenter studies on rheumatoid arthritis. Clin Exp Rheumatol 1993, 11:123-128.

25. Apolone G, Mosconi P: The Italian SF-36 Health Survey: translation, validation and norming. J Clin Epidemiol 1998, 51:1025-1036.

26. Bruce B, Fries JF: The Stanford Health Assessment Questionnaire: dimensions and practical applications. Health Qual Life Outcomes 2003, 1:20.

27. Scirè CA, Verstappen SM, Mirjafari H, Bunn DK, Lunt M, Montecucco C, Bruce IN, Symmons DP: Reduction of long-term disability in inflammatory polyarthritis by early and persistent suppression of joint inflammation: results from the Norfolk Arthritis Register. Arthritis Care Res (Hoboken) 2011, 63:945-952.

28. Apolone G, Mosconi P, Ware J: Questionnaire on health status SF-36 - User manual and a guide to interpretation of the results Milano: Guerini e Associati; 1997.

29. Ware JE, Gandek B, Kosinski M, Aaronson NK, Apolone G, Brazier J Bullinger M, Kaasa S, Leplege A, Prieto L, Sullivan M, Thunedborg K: The equivalence of SF-36 summary health scores estimated using standard and country-specific algorithms in 10 countries: results from the IQOLA Project. International Quality of Life Assessment. J Clin Epidemiol 1998, 51:1167-1170

30. Strand V, Khanna D, Singh JA, Forsythe A, Edwards NL: Improved healthrelated quality of life and physical function in patients with refractory chronic gout following treatment with pegloticase: evidence from phase III randomized controlled trials. J Rheumatol 2012, 39:1450-1457.

31. Perez-Ruiz F: Treating to target: a strategy to cure gout. Rheumatology (Oxford) 2009, 48(Suppl 2):ii9-ii14.

32. Humphreys JH, Verstappen SM, Mirjafari H, Bunn D, Lunt M, Bruce IN, Symmons DP: Association of morbid obesity with disability in early inflammatory polyarthritis: results from the Norfolk Arthritis Register. Arthritis Care Res (Hoboken) 2013, 65:122-126.

33. White $\mathbb{R}$, Royston $P$, Wood AM: Multiple imputation using chained equations: issues and guidance for practice. Stat Med 2011, 30:377-399.

34. Hirsch JD, Lee SJ, Terkeltaub R, Khanna D, Singh J, Sarkin A, Harvey J, Kavanaugh A: Evaluation of an instrument assessing influence of Gout on health-related quality of life. J Rheumatol 2008, 35:2406-2414.

35. Hirsch JD, Terkeltaub R, Khanna D, Singh J, Sarkin A, Shieh M, Kavanaugh A, Lee SJ: Gout disease-specific quality of life and the association with gout characteristics. Patient Relat Outcome Meas 2010, 2010:1-8.

doi:10.1186/ar4281

Cite this article as: Scirè et al:: Gout impacts on function and

health-related quality of life beyond associated risk factors and medical conditions: results from the KING observational study of the Italian Society for Rheumatology (SIR). Arthritis Research \& Therapy 2013 15:R101.

\section{Submit your next manuscript to BioMed Central and take full advantage of:}

- Convenient online submission

- Thorough peer review

- No space constraints or color figure charges

- Immediate publication on acceptance

- Inclusion in PubMed, CAS, Scopus and Google Scholar

- Research which is freely available for redistribution 